\title{
Diagnostic Approaches to Neuroendocrine Neoplasms of Unknown Primary Site
}

\author{
Alison May Berner ${ }^{a}$ b Christodoulos Pipinikas ${ }^{b}$ Anna Ryan ${ }^{c}$ Harpreet Dibra ${ }^{d}$ \\ Ismail Moghul $^{b}$ Amy Webster $^{b}$ Tu Vinh Luong ${ }^{e}$ Christina Thirlwell $^{b, f}$ \\ ${ }^{a}$ Department of Tumour Biology, Barts Cancer Institute, London, UK; ${ }^{b}$ Research Department of Oncology, UCL \\ Cancer Institute, London, UK; ' ${ }^{\mathrm{M}}$ Mount Vernon Cancer Centre, East and North Hertfordshire NHS Trust, Northwood, \\ UK; ${ }^{d}$ University of Birmingham, Birmingham, UK; ${ }^{e}$ Royal Free Hospitals NHS Trust, London, UK; ${ }^{f}$ University of Exeter \\ School of Medicine and Health, RILD Building, Exeter, UK
}

\section{Keywords}

Diagnosis $\cdot$ Neuroendocrine tumour $\cdot$ Neuroendocrine neoplasm $\cdot$ Imaging $\cdot$ Immunohistochemistry $\cdot$ Molecular . Unknown primary

\begin{abstract}
Neuroendocrine neoplasms (NENs) arise from cells of neuronal and endocrine differentiation. While they are a rare entity, an increasing proportion of patients with NEN present with metastatic disease and no evident primary site using routine imaging or histopathology. NENs of unknown primary site have a poorer prognosis, often due to the challenge of selecting appropriate evidence-based management. We review the available literature and guidelines for the management of NENs of unknown primary site including clinical features, biochemical tests, histopathology, imaging, surgical exploration and localised and systemic treatments. We also discuss novel molecular techniques currently under investigation to aid primary site identification.
\end{abstract}

\section{Introduction}

Neuroendocrine neoplasms (NENs) are rare tumours with cells that share markers of both endocrine and neuronal differentiation, including secretory granules and hormone production. Age-adjusted incidence is increasing and is 6.98 per 100,000 in the United States [1] and 8.84 per 100,000 in the United Kingdom [2]. Although originally thought to be indolent tumours by comparison to adenocarcinomas [3], grade 3 (G3) tumours can be highly aggressive, resulting in widespread metastases and poor prognosis $[1,4,5]$. The primary site of origin cannot be identified by routine imaging or histopathology in $12-$ $22 \%$ of cases $[1,6]$. This leads to uncertainty as to which is the most effective treatment approach. We review the literature on NENs of unknown primary, focussing on current clinical diagnostic methods for primary site identification and novel approaches to utilising molecular pathology. 


\section{Epidemiology}

Recent analysis of the Surveillance, Epidemiology, and End Results (SEER) data on NENs [1] showed an ageadjusted incidence of 0.84 per 100,000 population for NEN of unknown primary in the United States with a rising incidence in NENs overall. Comparison to analysis of 2004 SEER data by Yao et al. [7], shows that the incidence of unknown primary NEN has also increased (from 0.74 per 100,000), while its relative contribution to the total NEN diagnoses has reduced, due to increased diagnostic rates of small localized tumours of known primary.

NENs of unknown primary account for $12-22 \%$ of patients diagnosed with NEN [1] and $<5 \%$ of cancers of unknown primary (CUP) [8]. CUP has an incidence of 4.1 per 100,000 population per year in the United States [9]. Therefore NEN of unknown primary are a rare entity, but it is imperative to identify the primary site if possible given differing treatment options and outlook for intestinal, pancreatic and bronchial NENs.

A study using the National Cancer Registry of Spain [10] demonstrates the difficulties of studying the epidemiology of unknown primary NENs. In this study, $9 \%$ of patients were classified as having metastatic NEN of unknown primary, while $20 \%$ overall had their primary site as unknown or not registered. Unknown primary NEN can become a catch-all category for incomplete data in large studies, rather than a distinct diagnostic entity, subsequently skewing results.

\section{Prognosis}

Multivariate analysis by Dasari et al. [1] using the SEER registry data showed that median overall survival (mOS) for unknown primary was the lowest for any regional NEN site at 33 months. It also confirmed the primary site, histological grade and stage as significant factors for prognosis, although hazard ratios for "unknown" as a primary site were not given.

Catena et al. [11] showed an mOS of 48 months for their unknown primary NEN cohort and suggest that in the presence of liver metastases and NEN, unknown primary site is a poor prognostic factor. In a study of gastroenteropancreatic (GEP), NENs in the Spanish Cancer registry [10] mOS was 6.5 years (78 months) for NENs of unknown primary site and 4.2 years (50.4 months) for the subset with metastatic disease, compared with 12.1 years for all GEP NENs. The unknown primary site represented the poorest site-specific prognosis. Notably Ki67 and di- agnosis stage were the only independent prognostic variables in multivariate analysis, and all unknown primary NENs in this study were diagnosed with distant metastases.

By comparison with other CUPs, NENs of unknown primary are often thought of as having a favourable prognosis, along with extragonadal germ cell tumours in men and axillary metastases in women [8].

However, although survival rates for NENs are high, and will likely improve with advances in therapy, unknown primary site continues to represent a poor prognostic factor, particularly given that these tumours are diagnosed at an advanced stage. Improved identification of primary site by both traditional and novel methods will enable better evidence-based management, resulting in improved outcomes.

\section{Histology}

Histological grading in neuroendocrine tumours according to the World Health Organisation (WHO) $[4,12$, 13 ] varies according to the tissue of origin. For GEP, NEN well-differentiated neuroendocrine tumours (WDNET) are classified as grade 1 to G3, whereas poorly differentiated neuroendocrine carcinoma (PDNEC) are G3 by definition and include small or large cell types according to morphology. Mixed neuroendocrine-non-neuroendocrine neoplasms may also be found and may be referred to as mixed adenoneuroendocrine carcinomas in preceding classification systems. Bronchial and thymic WDNETs are divided into typical or atypical subtypes, while NECs are also divided into small and large cell types. These classifications, according to necrosis, mitoses and Ki67 are presented in Table 1. However, it should be noted that the 2017 classification for pancreatic NEN [13] is already being widely applied for GEP, while an updated WHO classification for non-pancreatic gastrointestinal (GI) NEN is expected in 2019.

Studies have given conflicting evidence as to the proportions of WDNETs and PDNECs in the unknown primary cohort. Catena et al. [11] performed a retrospective analysis of NENs of unknown primary at their centre and found $69.5 \%$ to be well differentiated and $4 \%$ to be poorly differentiated, with the remaining unclassifiable. However, it should be noted that this study was performed using the previous WHO classification. A retrospective analysis of 22 GEP NENs of unknown primary referred to a surgical clinic [14] found them all to be "low grade" and with an identifiable primary at surgical debulking. 
Table 1. Comparative Classification of bronchial, pancreatic and other GI NENs according to most recent WHO publications

\begin{tabular}{|c|c|c|c|c|c|}
\hline \multirow{2}{*}{$\frac{\text { Tissue of origin }}{\text { Bronchial (2015) }}$} & \multicolumn{3}{|c|}{ WDNETs } & \multicolumn{2}{|l|}{ NECs } \\
\hline & Typical & & Atypical & Large cell & Small cell \\
\hline Necrosis & No & & None/focal/punctate & Yes & Yes \\
\hline Mitoses $/ \mathrm{mm}^{2}$ & $<2$ & & $2-10$ & $>10$ & $>10$ \\
\hline Ki67, \% & $\leq 5$ & & $\leq 20$ & $40-80$ & $50-100$ \\
\hline Pancreatic (2017) & G1 & $\mathrm{G} 2$ & G3 & Large cell & Small cell \\
\hline Mitoses/HPF & $<2$ & $2-20$ & $>20$ & $>20$ & $>20$ \\
\hline Ki67 & $\leq 2$ & $3-20$ & $>20$ & $>20$ & $>20$ \\
\hline Other GI (2010) & G1 & & G2 & Large cell & Small cell \\
\hline Mitoses/10 HPF & $<2$ & & $2-10$ & $>20$ & $>20$ \\
\hline Ki67 & $\leq 2$ & & $3-20$ & $>20$ & $>20$ \\
\hline
\end{tabular}

Note that for gastroenteropancreatic NEN, NECs are poorly differentiated by definition and known as PDNEC.

GI, gastrointestinal; WHO, World Health Organisation; WDNETs, well-differentiated neuroendocrine tumours; NEC, neuroendocrine carcinoma; HPF, high power field; NEN, neuroendocrine neoplasm.

This is likely to be a highly biased sample, given that a lower grade and stage of tumour is likely to be referred for surgical management.

Determining that a CUP is a NEN of unknown primary may rely on immunohistochemical (IHC) stains as well as cellular morphology. These include chromogranin, synaptophysin, protein gene product 9.5 and CD56 [15]. IHC may also help to determine the primary site, and those which are routinely used can be found in Table 2 [16]. CDX2 is a useful marker of intestinal NEN $[17,18]$. However, as a transcription factor associated with GI differentiation [19], it is also found in gastrinpositive pancreatic NENs [20] and colorectal adenocarcinoma [21].

In the case of WDNETs, Thyroid Transcription Factor 1 (TTF1) positivity may suggest a bronchial primary, as it is present in $43 \%$ of cases [18]. However, it is not specific in PDNECs, as it is also present in 50\% of small cell tumours at other sites [22]. It is also positive in thyroid tumours, as it plays a role in the development of thyroid and respiratory development [23]. Transcription factor PDX1 and secretory protein NESP-55 have been used in combination to identify pancreatic NENs by IHC [24] with a sensitivity of $30-40 \%$. The finding of dual positivity of PDX-1 and NESP-55 staining and negativity for TTF1 and CDX-2 staining is $97 \%$ specific for pancreatic NEN [24]. Chan et al. [91] used a similar panel, through substituting NESP-55 for protein keratin 7 (CK7). CK7 was found to have greater sensitivity though less specificity
Table 2. Summary of histopathological markers used to identify NEN primary site

\begin{tabular}{|c|c|}
\hline Marker & NENs demonstrating positive staining \\
\hline $\mathrm{CDX} 2$ & $\begin{array}{l}\text { Gastrin-positive pancreatic } \\
\text { Small intestinal }\end{array}$ \\
\hline $\mathrm{Ck} 7$ & Bronchial \\
\hline Isl-1 & $\begin{array}{l}\text { Pancreatic } \\
\text { Rectal }\end{array}$ \\
\hline NESP-55 & Pancreatic \\
\hline PAX-6, PAX-8 & $\begin{array}{l}\text { Pancreatic } \\
\text { Duodenal } \\
\text { Rectal }\end{array}$ \\
\hline PDX-1 & Pancreatic \\
\hline Progesterone receptor & Pancreatic \\
\hline Serotonin & $\begin{array}{l}\text { Appendiceal } \\
\text { Ileal }\end{array}$ \\
\hline TTF-1 & $\begin{array}{l}\text { Bronchial } \\
\text { Small-cell NECs of other sites }\end{array}$ \\
\hline
\end{tabular}

NEN, neuroendocrine neoplasm; CDX2, caudal type homeobox 2; Ck7, cytokeratin 7; Isl-1, ISL LIM homeobox 1; NESP-55, neuroendocrine secretory protein 55; PAX, paired box protein; PDX-1, pancreatic and duodenal homeobox 1; TTF1, thyroid transcription factor 1 ; NEC, neuroendocrine carcinoma.

for bronchial NENs. PAX-8 and Isl-1 can be used as markers for both pancreatic and rectal NEN $[25,26]$. Serotonin has utility in identifying tumours of EC cells originating in the ileum or appendix [27]. There is no consen- 
Table 3. Functional NEN types with relevant symptoms and blood markers ULN

\begin{tabular}{|c|c|c|}
\hline Tumour & Symptoms & Blood markers \\
\hline Insulinoma & $\begin{array}{l}\text { May resolve with eating } \\
\text { Dizziness } \\
\text { Confusion } \\
\text { Drowsiness } \\
\text { Sweating }\end{array}$ & $\begin{array}{l}\text { Insulin }<3.0 \mathrm{mU} / \mathrm{L} \\
\text { Pro-insulin } \geq 5.0 \mathrm{pmol} / \mathrm{L} \\
\text { C-peptide } \geq 0.6 \mathrm{ng} / \mathrm{mL} \\
\text { Plasma blood glucose }<3.0 \mathrm{mmol} / \mathrm{L}\end{array}$ \\
\hline Gastrinoma & $\begin{array}{l}\text { Zollinger-Ellison Syndrome } \\
\text { Abdominal pain } \\
\text { Diarrhoea } \\
\text { Reflux symptoms } \\
\text { Peptic ulceration }\end{array}$ & Fasting serum gastrin $>10 \times \mathrm{ULN}$ \\
\hline VIPoma & $\begin{array}{l}\text { Verner-Morrison Syndrome } \\
\text { Watery diarrhoea } \\
\text { Dehydration } \\
\text { Hyperkalaemia }\end{array}$ & Vasoactive intestinal peptide $>100 \mathrm{pg} / \mathrm{mL}$ \\
\hline Glucagonoma & $\begin{array}{l}\text { Diarrhoea } \\
\text { Steathorrhoea } \\
\text { Weight loss } \\
\text { Glucose intolerance }\end{array}$ & Plasma glucagon $>1,000 \mathrm{pg} / \mathrm{mL}$ \\
\hline Somatostatinoma & $\begin{array}{l}\text { Weight loss } \\
\text { Gallstones } \\
\text { Diarrhoea }\end{array}$ & Fasting plasma somatostatin $>30 \mathrm{pg} / \mathrm{mL}$ \\
\hline
\end{tabular}

ULN, upper limit of normal; NEN, neuroendocrine neoplasm.

sus recommendation in current guidelines with regards to IHC panels to NEN subtype classification [28, 29], although several combination panels have been suggested $[24,30]$.

\section{Localising the Primary}

\section{Clinical Features}

Both functioning and non-functioning NENs may present with symptoms related to the site of primary tumour or metastases that help localisation. These include pain (including liver capsule pain) or obstructive symptoms from pressure on vessels, airways, GI tract or biliary system. Fatigue and shortness of breath may result from anaemia as a result of bleeding anywhere along the GI tract. Bronchial NENs may cause chest symptoms, including recurrent infection, haemoptysis or dyspnoea [31].

In the case of functioning NENs, it is often easier to determine the primary site (typically pancreas or small bowel) particularly if the relevant gut hormone is identi- fied. Table 3 lists the symptoms of the most common types. When a functioning tumour releases vasoactive substances that bypass first-pass metabolism, for example, in the case of liver metastases, this can result in carcinoid syndrome [32]. This is most common in small bowel NENs and rarer in unknown primary NENs [11]. Symptoms include palpitations, flushing, sweating and diarrhoea [33]. Bronchial NENs occasionally produce adrenocorticotropic hormone, resulting in Cushing's syndrome [12].

\section{Biochemical Tests}

Secretion of chromogranin A into blood is fairly ubiquitous across NENs [34] and is therefore unlikely to be of assistance in determining the primary site once a histological diagnosis is made. 24-h urinary 5-hydroxyindoleacetic acid, a break-down product of serotonin is more commonly raised in small intestinal NENs with high levels associated with metastatic disease [35].

There are also biochemical markers, which may be used to identify NEN primary site, but the sensitivity and specificity of each vary according to the tissue type, and 
particular functional tumours can originate in $>1$ organ. Raised serum gastrin may suggest a duodenal primary, occurring in $60-80 \%$ of cases, with the remaining in the pancreas [36]. Neurokinin A may be raised in distal small bowel and large bowel NENs. Pancreatic polypeptide may be a marker of non-functioning pancreatic and rectal NENs [37]. Functioning pancreatic NENs may be identified from circulating gut hormones. Those commonly used are listed in Table 3. Rarely pancreatic NENs have been known to secrete parathyroid hormone-related protein, renin, luteinising hormone, erythropoietin, insulinlike growth factor, neurotensin, ghrelin and cholecystokinin. Up to $10 \%$ of VIPomas may be adrenal or paraganglionic, and $44 \%$ of somatostatinomas are found in the small bowel [36].

\section{Imaging}

For patients with biopsy proven NEN, without an obvious primary site, NCCN Guidelines [28] recommend computerised tomography (CT) of the chest and multiphasic CT or magnetic resonance imaging (MRI) of the abdomen and pelvis. Should this not be diagnostic, other recommended investigations to be considered are somatostatin receptor scintigraphy (SRS) or gallium-68 (Ga-68) DOTA-peptide positron emission tomography (PET)/CT, endoscopic ultrasound (EUS), upper GI endoscopy and/or colonoscopy. In cases of poorly differentiated NEN, Fluorodeoxyglucose (FDG) PET/CT and brain imaging are also recommended. The role of MRI is mainly for localisation of metastases, particularly in the liver, rather than in localisation of a primary tumour [38].

UK guidelines [39] advocate the use of Ga-68 DOTApeptide $\mathrm{PET} / \mathrm{CT}$ in all cases of unknown primary and European guidelines $[40,41]$ also recommend that this modality replaces SRS due to improved image quality. Retrospective studies have found sensitivities ranging from 7 to $76 \%$ for CT scan and $2-57 \%$ for SRS $[6,42-44]$. Crosssectional imaging studies may not identify the primary directly, but mesenteric lymphadenopathy may indicate an occult small bowel primary as it has been found to be present in up to half of such cases [45]. CT enteroclysis is of particular utility in small bowel NENs with 1 study reporting sensitivity of $100 \%$ and specificity of $96.2 \%$ a cohort of 44 patients with suspected GI carcinoid [46].

Sensitivity of endoscopic studies is difficult to interpret from small cohorts, as the different modalities (colonoscopy, upper GI endoscopy or EUS) are focussed towards specific subtypes (e.g., EUS and pancreatic primary), the numbers of which will vary within the unknown cohort of the study. Bartlett et al. [44] report a sensitivity of $60 \%$ for EUS and $50 \%$ for capsule endoscopy. Wang et al. [6] report the sensitivities of colonoscopy in diagnosing ileal and colonic NENs to be 61 and $87 \%$ respectively.

Ga-68 labelled PET/CT tracers offer improved affinity to the somatostatin receptor and superior spatial resolution compared to traditional SRS [47]. Image acquisition is also faster, and radiation exposure is lower [48]. There are $3 \mathrm{Ga}-68$ labelled DOTA-peptides (DOTA-TOC, DOTA-NOC, and DOTATATE) with varying affinities for different somatostatin receptors [47, 49]. Naswa et al. [50] carried out a prospective study using Ga-68-DOTA-NOC $\mathrm{PET} / \mathrm{CT}$ to localise primary tumour in $72 \mathrm{NEN}$ patients. They found a sensitivity of $78 \%$ though notably all patients included had primary site eventually identified by other means (CT, MRI, endoscopy or histopathology). In a study, Ambrosini et al. [51] found that Ga-68-DOTANOC was able to localise 3 out of 4 occult primary NENs. In a prospective study of 59 patients with NEN of unknown primary site, Ga-68-DOTA-NOC PET/CT was able to localise the primary $59 \%$ of patients [52]. Gabriel et al. [53] report a sensitivity of $97 \%$ for Ga-68-DOTATOC PET/CT in a cohort that included NENs of previously unknown primary, though in other studies this has been found to be lower [54]. Even in the setting of negative or low uptake on SRS, Ga-68-DOTOTATE PET/CT has been shown to detect up to $74 \%$ of NEN lesions [31].

FDG-PET has a diagnostic role in NENs of unknown primary with a higher proliferation index, as uptake has been shown to rise with Ki67 as 68Ga-DOTATATE PET uptake reduces [55]. Abgral et al. [56] showed FDG-PET to have an $88 \%$ sensitivity in detecting the primary in a series of NENs with Ki67 $>10 \%$, higher than that of SRS in the same study. Given that NENs with a lower proliferation index are more likely to show positivity on PET using Ga-68 labelled DOTA-peptides, it would seem logical to use this in combination with FDG-PET. When this strategy was employed by Kayani et al. [57], they found a combined sensitivity of $92 \%$ compared to $82 \%$ for $68 \mathrm{Ga}$ DOTATATE PET/CT alone and 66\% 18F-FDG PET/CT. Both of these studies were in the setting of known primary NENs of various sites. Given the association with Ki-67, FDG PET/CT also acts to identify more aggressive tumours more likely to respond to chemotherapy than targeted therapies.

NENs are known to accumulate L-3,4-dihydroxyphenylalanine, leading to the use of $6-18 \mathrm{~F}-$ fluoro-L-3,4-dihydroxyphenylalanine PET for imaging, where it has shown particular sensitivity in the detection of skeletal lesions [58]. Imperiale et al. [59] utilised 18F-fluoroL-3,4-dihydroxyphenylalanine PET in a series of patients 
with NEN of unknown primary and negative SRS. Sensitivity was $44 \%$, and positivity was associated with higher urinary 5-hydroxyindoleacetic acid and serum chromogranin $\mathrm{A}$, suggesting a subgroup of patients where this imaging modality should be considered more readily.

\section{Surgery for Diagnosis}

Several small studies have suggested that of GEP NENs of unknown primary are referred for surgery, a small bowel primary is most likely and thus, aggressive surgical debulking is recommended [42]. Wang et al. [14] report on 22 patients with NEN of unknown primary referred for surgical exploration, with the primary site identified in all cases (19 small intestine and 3 pancreatic) and all tumours being low grade. Massimino et al. [43] carried out a larger retrospective study of 63 patients and compared surgical exploration with imaging techniques for diagnosis. They found a sensitivity of $79 \%$ for surgical exploration compared with $6.7 \%$ for CT scan and $2 \%$ for SRS. In $70 \%$ of patients, a small bowel primary was present and in $22 \%$ the primary remained occult, with other sites identified as appendix, pancreas, colon and ovary. These studies are subject to some level of referral bias, as patients with unknown primary NEN with more extensive disease or poorer performance status are less likely to be referred for surgery. However, a more recent study by Keck et al. [42] retrospectively reviewed the records of 197 patients with liver metastases and in situ primary NEN. $92.5 \%$ of patients had their primary tumour identified pre-operatively, and only $4 \%$ had occult primaries following both pre-operative diagnostic studies and surgery. Although small intestine was the most common primary site identified (67.2\%), those who had imaging or other modalities alone without surgery (due to patient choice or comorbidity precluding surgery), were most likely to be diagnosed with pancreatic primaries (30/44 patients). This is likely to represent a bias in imaging methods, as it is challenging to visualise small bowel tumours with conventional cross-sectional imaging.

While surgery has the added ability to debulk metastatic disease, as well as diagnose primary site, it is important to acknowledge the associated morbidity and mortality when making decisions around surgery. In the study by Keck et al. [42], only $4.5 \%$ of patients had an additional diagnostic value from surgery in terms of primary site localisation. Survival data from these retrospective surgical studies is scarce and difficult to interpret, given the inherent bias that exists in selecting patients for surgery and debulking their disease.

\section{Molecular Diagnostics}

Several studies have utilised molecular methods to profile neuroendocrine tumours for both research and diagnostics. Over a decade ago, Duerr et al. [60] demonstrated differences in transcriptional profiles between pancreatic and GI NENs, and between pancreatic WDNETs and PDNECs. Kaemmerer et al. [61] used RNA expression profiling to attempt to classify NEN metastases as intestinal or pancreatic. They analysed the expression of 2 genes, CD302 and PPWD1, by microarray and achieved a diagnostic accuracy of $80 \%$. Sensitivity was $75 \%$ for ileal NENs and 38\% for pancreatic NENs. Sherman et al. [62] performed a similar study for pancreatic and small bowel NENs using quantitative polymerase chain reaction to measure the expression of 4 genes, bombesin-like receptor-3, opioid receptor kappa-1, oxytocin receptor, and secretin receptor. They achieved $94.1 \%$ overall accuracy in their training set and $92.9 \%$ accuracy in an independent validation set of liver metastases. However, these studies used tissue that was preserved by freezing and "RNA-later" solution respectively. These methods, while common in research, are not used in clinical diagnostic laboratories, therefore limiting the ability to translate these studies. Formalin-fixation and embedding in paraffin is the most commonly used method of tissue preservation. Kerr et al. [63] were able to utilise a 92-gene reverse transcription PCR expression assay to distinguish between a wide range of subtypes of NEN preserved in this way. They achieved 95\% accuracy. However, laser microdissection was used in the samples preparation prior to analysis, therefore limiting translation to routine clinical diagnosis.

Compared to other tumour types, NENs have a low number of somatic mutations [64-66] whilst epigenetic modifications such as promoter methylation are more common [67]. Those somatic mutations that do occur commonly tend to be in genes associated with epigenetic modifications such as chromatin remodelling and methylation. Pancreatic NENs are known to have frequent mutations and loss of expression of chromatin modifiers MEN1, DAXX and ATRX [66, 68]. Further, loss of DAXX expression is associated with genome-wide methylation changes and poorer prognosis [69]. Given the frequency of $A T R X$ and DAXX loss in pancreatic NEN, it has also been used as a marker for IHC.

Genome-wide DNA methylation analysis, in combination with sequencing and copy number analysis, has also been used to subtype small intestinal NENs [65]. Three groups characterised by differences in chromo- 
some 18 loss of heterozygosity, CDKN1B mutations, copy number variations and $\mathrm{CpG}$ island methylator phenotype had significant differences in progression-free survival (PFS), which ranged from 21 months to not yet reached at 10 years. Karpathakis et al. [70] also showed that small intestinal NEN liver metastases demonstrate progressive metastasis-related global hypomethylation compared to the primary tumour. Further, a panel of 21 epigenetically dysregulated genes was found that distinguished small intestinal NENs from other tumour types and normal tissue in both studies. These genes showed progressive changes in methylation and expression levels in liver metastases compared to primary tumours $[65,70]$. DNA methylation studies of small intestinal NENs have also demonstrated significantly increased methylation tumour suppressor genes, RUNX3, TP73, and CHFR [71].

Given this epigenetic dysregulation in NENs, our group recently carried out a study using methylation array data to determine NEN tissue-of-origin for pancreatic, small intestinal and unknown primary NENs. DNA from formalin-fixed paraffinembedded tissue from 76 pancreatic NEN, 53 small intestinal NEN and 13 NENs of unknown primary were analysed on the Illumina $450 \mathrm{~K}$ methylation array. We performed Differentially Methylated Position analysis for a training subset of 97 pancreatic NENs and small intestinal NEN training samples and methylation values for these Differentially Methylated Positions were used as input for an ensemble learning Support Vector Machine training algorithm [72] to create the PUnNETS (Prediction of Unknown Neuroendocrine Tumour Site) classifier [73]. PUnNETS was then used to predict the tissue of origin for 32 validation samples of known primary (pancreatic and small intestinal NENs) with $100 \%$ accuracy. Although it was not possible to know the true primary site for the 13 unknown samples, the classifier had high confidence scores of $>95 \%$ for all predictions for these samples. This work will be validated with a larger independent cohort of NEN subtypes including bronchial in order to development a methylation-based classifier for NENs, similar to those developed for CUP [74] and paediatric brain tumours [17].

\section{Treatment}

Identification of a primary site for NEN determines the evidence-based management pathway for the patient. Treatment algorithms, particularly in the metastatic setting, differ according to subtype. Although NEN of unknown primary site is discussed in several guidelines for
NEN $[28,39-41]$, there are no specific recommendations for the treatment of this entity. Surgery and/or ablative therapies (e.g., radiofrequency ablation, transarterial embolization) offer the only chance of cure [29] or may be used to debulk and relieve symptoms. The liver is commonly the initial site of metastasis, and a prospective observational study of liver-directed therapy for isolated liver metastases in NEN found mOS figures of 160 months for hepatic resection, 123 months for radiofrequency ablation and 84 months for chemo-embolisation compared with 70 and 38 months for systemic therapy and observation respectively [75]. Knowledge of the site of the primary is important for giving patients accurate prognostic information. An observational study of liver-directed therapy in metastatic NEN found mOS to be significantly longer for small intestinal NEN at 99.5 months compared to only 66.1 months for pancreatic NENs [75].

Somatostatin analogues octreotide and lanreotide are used in multiple NEN subtypes for both symptom control in functioning tumours [29] and as for disease control, achieving stable disease in up to $60 \%$ of WDNETs [76]. Their use at diagnosis of metastatic disease is supported by the PROMID trial [77] with most experience in intestinal and pancreatic subtypes. The CLARINET study included 26 patients with unknown primary NEN, 15 of whom received lanreotide with PFS not reached (15 months for placebo) [78].

Chemotherapy is recommended for treatment of all bronchial NENs, pancreatic NENs and all G3 NENs [29, 79-81]. Use in small intestinal NENs is restricted to high disease burden due to the lower response rate of 15\% [79, 82]. Stoyianni et al. [83] performed a systematic review of the treatment of NEN of unknown primary. Eight studies undertaken between 1988 and 2010 reported mOS in where patients treated with chemotherapy and this ranged from 12 to 40 months. Twelve studies reported an overall response rate to chemotherapy, and this ranged from 0 to $100 \%$. The studies were heterogeneous for sample size and chemotherapy used, given that they were mostly retrospective analyses. However, Hainsworth et al. [8] carried out a prospective phase II trial of paclitaxel, carboplatin and etoposide in PDNEC that included 48 patients with unknown primary NEN. Of these patients, 55\% had a partial or complete response, and $31 \%$ had stable disease. PFS and OS were 7.5 and 14.1 months, respectively, compared with 10.7 and 15.1 months in the known primary group.

Targeted agents such as everolimus and sunitinib are used in the treatment of NENs with high response rates and improved survival [84-86]. Everolimus is also indi- 


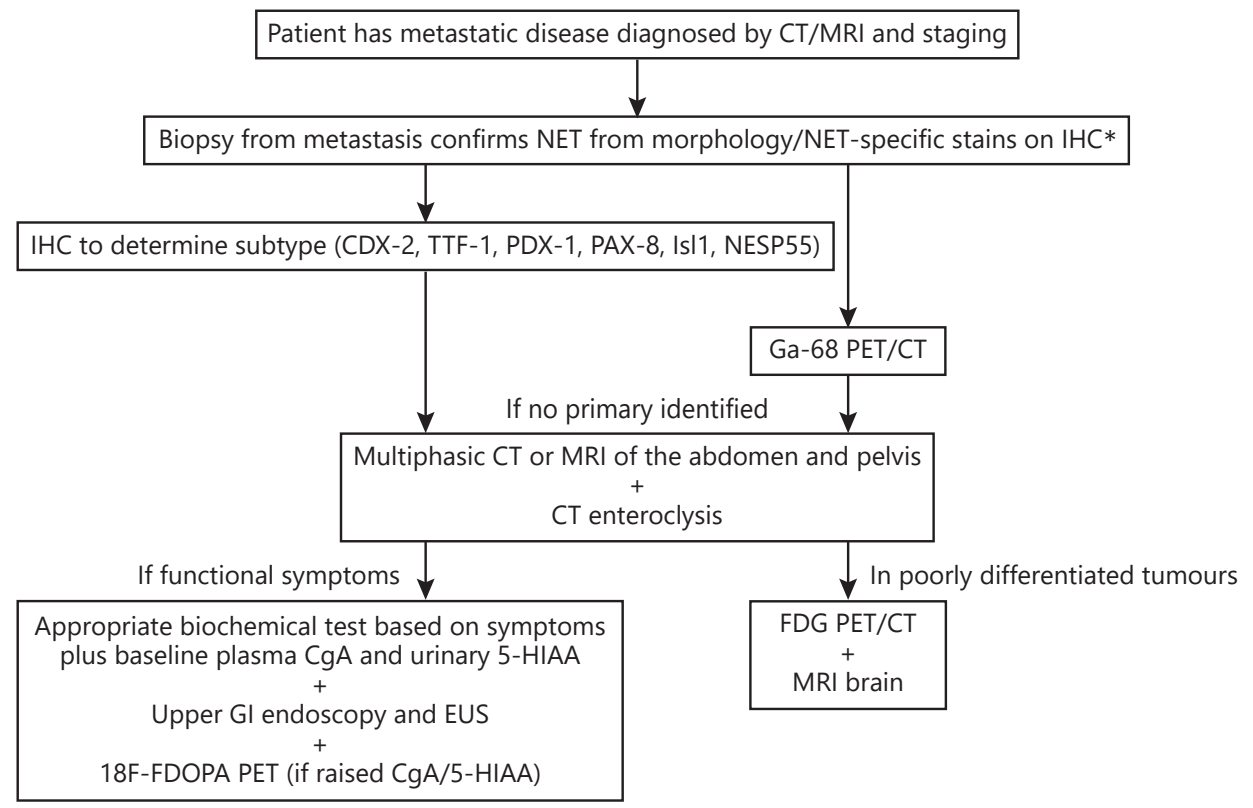

Fig. 1. Suggested diagnostic algorithm for neuroendocrine tumours of unknown primary. * Chromogranin/synaptophysin/PGP9.5/CD56. IHC, immunohistochemistry; SRS, somatostatin receptor scintigraphy; CgA, chromogranin A, 5-HIAA, 5-hydroxyindoleacetic acid; EUS, endoscopic ultrasound; CT, computerised tomography; MRI, magnetic resonance imaging; NET, neuroendocrine tumours; PET, positron emission tomography; FDG, fluorodeoxyglucose.

cated in intestinal and bronchial NEN but as second-line therapy following the publication of the RADIANT-4 study $[85,87]$. This study also included 36 patients with NEN of unknown primary site. mPFS was 13.6 months with everolimus and 7.5 months with placebo. These figures were 13.1 and 5.4 months, respectively, for GI NEN. The phase II study of sunitinib in advanced NEN [88] included only a single patient with unknown primary NEN, while the major phase III study of sunitinib was restricted to pancreatic NEN [86]. As sunitinib has not shown impressive activity in NEN subtypes other than pancreatic [89], it is difficult to justify its use in patients with NEN where the primary site cannot be identified.

\section{Conclusion}

NEN of unknown primary is a clinically important entity with rising incidence and poorer prognosis compared to other NEN subtypes. There are a number of current guidelines discussing its diagnosis and management [28, $29,39-41]$, and the topic has also been the subject of re- view by Alexandraki et al. [30]. From these, and current evidence, we suggest a diagnostic algorithm, as shown in Figure 1, which aims to be a more step-by-step approach than those previously produced $[30,90]$. This assumes that a patient has been diagnosed with de novo metastatic disease and investigated through a carcinoma of unknown primary pathway with standard staging CT chest, abdomen and pelvis and biopsy confirmation of a neuroendocrine tumour by morphology or IHC. If further IHC cannot confirm a subtype, then it is suggested to proceed straight to Ga-68 DOTA-peptide PET/CT due to its superior detection rate over SRS [47]. If this fails to localise the primary then both SRS and multiphase abdominal imaging are suggested, the latter to attempt to identify small bowel tumours in particular. If the primary site has still not been identified, then the order in which further tests are carried out will depend on the clinical context. For example, if the patient has symptoms of a functional tumour, then this would favour a pancreatic primary and EUS may be attempted, whereas poorly differentiated tumours are more likely to have a higher level of metabolic activity and so FDG-PET may be performed. In reality, it 
is likely that most of the investigations listed will be requested eventually if the primary has site has still not been found. Even if the primary is not located, these tests may give additional information to guide treatment. For example, the level of SRS-positivity will be indicative of the efficacy of the somatostatin analogues for the patient.

Meanwhile, advances continue to be made in histopathological, imaging and molecular diagnostic techniques. Although currently confined to a research setting, RNA expression analysis and/or methylation profiling may in future enable localisation of the primary tumour. This will facilitate better evidence-based management of patients, with access to targeted agents and enrolment in clinical trials, which will hopefully result in improved survival outcomes.

\section{Disclosure Statement}

The authors declare that they have no conflicts of interest to disclose.

\section{Funding Sources}

This research did not receive any specific grant from any funding agency in the public, commercial or not-for-profit sector. C.T.: funded by NET Research Foundation, BRC, ECMC. A.M.B.: funded by Cancer Research UK.

\section{Author Contribution}

A.M.B. and C.T.: both devised the manuscript concept and contributed to manuscript preparation, editing and review. All authors contributed to generation of original data for PunNETS discussed in the "Molecular Diagnostics" section. C.P., A.R., H.D., I.M., A.W., and T.V.L.: participated in manuscript editing and review.

\section{References}

1 Dasari A, Shen C, Halperin D, Zhao B, Zhou $\mathrm{S}, \mathrm{Xu} \mathrm{Y}$, et al. Trends in the incidence, prevalence, and survival outcomes in patients with neuroendocrine tumors in the United States. JAMA Oncol. 2017 Oct;3(10):1335-42.

2 Genus T, Bouvier C, Wong K, Srirajaskanthan R, Rous B, Talbot D, et al. Incidence and prevalence of neuroendocrine tumours in England. Endocr Abstr. 2017;52 OC3. DOI: 10.1530/endoabs.52.OC3.

3 Oberndorfer S. Karzinoide tumoren des dunndarms. Frankf Z Pathol. 1907;1:426-32.

4 Bosman FT, Carneiro F, Hruban RH, Theise ND. WHO classification of tumours of the digestive system. World Health Organization; 2010.

5 Travis WD, Brambilla E, Burke A, Marx A, Nicholson AG. WHO classification of tumours of the lung, pleura, thymus and heart. International Agency for Research on Cancer; 2015.

6 Wang SC, Parekh JR, Zuraek MB, Venook AP, Bergsland EK, Warren RS, et al. Identification of unknown primary tumors in patients with neuroendocrine liver metastases. Arch Surg. 2010 Mar;145(3):276-80.

7 Yao JC, Hassan M, Phan A, Dagohoy C, Leary C, Mares JE, et al. One hundred years after "carcinoid": epidemiology of and prognostic factors for neuroendocrine tumors in 35,825 cases in the United States. J Clin Oncol. 2008 Jun;26(18):3063-72.

8 Hainsworth JD, Spigel DR, Litchy S, Greco FA. Phase II trial of paclitaxel, carboplatin, and etoposide in advanced poorly differentiated neuroendocrine carcinoma: a Minnie Pearl Cancer Research Network Study. J Clin Oncol. 2006 Aug;24(22):3548-54.
9 Mnatsakanyan E, Tung WC, Caine B, SmithGagen J. Cancer of unknown primary: time trends in incidence, United States. Cancer Causes Control. 2014 Jun;25(6):747-57.

10 Garcia-Carbonero R, Capdevila J, CrespoHerrero G, Díaz-Pérez JA, Martínez Del Prado MP, Alonso Orduña V, et al. Incidence, patterns of care and prognostic factors for outcome of gastroenteropancreatic neuroendocrine tumors (GEP-NETs): results from the National Cancer Registry of Spain (RGETNE). Ann Oncol. 2010 Sep;21(9):1794-803.

11 Catena L, Bichisao E, Milione M, Valente M, Platania M, Pusceddu S, et al. Neuroendocrine tumors of unknown primary site: gold dust or misdiagnosed neoplasms? Tumori. 2011 Sep-Oct;97(5):564-7.

12 Travis WD. Lung tumours with neuroendocrine differentiation. Eur J Cancer. 2009 Sep; 45 Suppl 1:251-66.

13 Inzani F, Petrone G, Rindi G. The New World Health Organization Classification for Pancreatic Neuroendocrine Neoplasia. Endocrinol Metab Clin North Am. 2018 Sep;47(3): $463-70$.

14 Wang YZ, Chauhan A, Rau J, Diebold AE, Opoku-Boateng A, Ramcharan T, et al. Neuroendocrine tumors (NETs) of unknown primary: is early surgical exploration and aggressive debulking justifiable? Chin Clin Oncol. $2016 \mathrm{Feb} ; 5(1): 4$.

15 Oien KA. Pathologic evaluation of unknown primary cancer. Semin Oncol. 2009 Feb; 36(1):8-37.

16 Yazdani S, Kasajima A, Ogata H, Felizola SJ, Nakamura Y, Onodera Y, et al. Progesterone Receptor Isoforms A and B in Pancreatic
Neuroendocrine Tumor. Neuroendocrinology. 2015;101(4):309-20.

17 Capper D, Jones DT, Sill M, Hovestadt V, Schrimpf D, Sturm D, et al. DNA methylation-based classification of central nervous system tumours. Nature. 2018 Mar;555(7697): 469-74.

18 Lin X, Saad RS, Luckasevic TM, Silverman JF, Liu Y. Diagnostic value of CDX-2 and TTF-1 expressions in separating metastatic neuroendocrine neoplasms of unknown origin. Appl Immunohistochem Mol Morphol. 2007 Dec; 15(4):407-14.

19 Silberg DG, Swain GP, Suh ER, Traber PG $\mathrm{Cdx} 1$ and $\mathrm{cdx} 2$ expression during intestinal development. Gastroenterology. 2000 Oct; 119(4):961-71.

20 Hermann G, Konukiewitz B, Schmitt A, Perren A, Klöppel G. Hormonally defined pancreatic and duodenal neuroendocrine tumors differ in their transcription factor signatures : expression of ISL1, PDX1, NGN3, and CDX2. Virchows Arch. 2011;459:147.

21 De Lott LB, Morrison C, Suster S, Cohn DE, Frankel WL. CDX2 is a useful marker of intestinal-type differentiation: a tissue microarraybased study of 629 tumors from various sites. Arch Pathol Lab Med. 2005 Sep;129(9):1100-5.

22 Jagirdar J. Application of immunohistochemistry to the diagnosis of primary and metastatic carcinoma to the lung. Arch Pathol Lab Med. 2008 Mar;132(3):384-96.

23 Lazzaro D, Price M, de Felice M, Di Lauro R. The transcription factor TTF- 1 is expressed at the onset of thyroid and lung morphogenesis and in restricted regions of the foetal brain. Development. 1991 Dec;113(4):1093-104. 
24 Srivastava A, Hornick JL. Immunohistochemical staining for CDX-2, PDX-1, NESP55 , and TTF- 1 can help distinguish gastrointestinal carcinoid tumors from pancreatic endocrine and pulmonary carcinoid tumors. Am J Surg Pathol. 2009 Apr;33(4):626-32.

25 Koo J, Mertens RB, Mirocha JM, Wang HL, Dhall D. Value of Islet 1 and PAX8 in identifying metastatic neuroendocrine tumors of pancreatic origin. Mod Pathol. 2012 Jun; 25(6):893-901.

26 Koo J, Zhou X, Moschiano E, De Peralta-Venturina M, Mertens RB, Dhall D. The immunohistochemical expression of islet 1 and PAX8 by rectal neuroendocrine tumors should be taken into account in the differential diagnosis of metastatic neuroendocrine tumors of unknown primary origin. Endocr Pathol. 2013 Dec;24(4):184-90.

27 Solcia E, Vanoli A. Histogenesis and natural history of gut neuroendocrine tumors: present status. Endocr Pathol. 2014 Jun;25(2): $165-70$.

28 Clark OH, Benson AB 3rd, Berlin JD, Choti MA, Doherty GM, Engstrom PF, et al.; NCCN Neuroendocrine Tumors Panel Members. NCCN Clinical Practice Guidelines in Oncology: neuroendocrine tumors. J Natl Compr Canc Netw. 2009 Jul;7(7):712-47.

29 Pavel M, O’Toole D, Costa F, Capdevila J, Gross D, Kianmanesh R, et al.; Vienna Consensus Conference participants. ENETS Consensus Guidelines Update for the Management of Distant Metastatic Disease of Intestinal, Pancreatic, Bronchial Neuroendocrine Neoplasms (NEN) and NEN of Unknown Primary Site. Neuroendocrinology. 2016; 103(2):172-85

30 Alexandraki K, Angelousi A, Boutzios G, Kyriakopoulos G, Rontogianni D, Kaltsas G. Management of neuroendocrine tumors of unknown primary. Rev Endocr Metab Disord. 2017 Dec;18(4):423-31.

31 Srirajaskanthan R, Kayani I, Quigley AM, Soh J, Caplin ME, Bomanji J. The role of $68 \mathrm{Ga}$ DOTATATE PET in patients with neuroendocrine tumors and negative or equivocal findings on 111In-DTPA-octreotide scintigraphy. J Nucl Med. 2010 Jun;51(6):875-82.

32 Caplin ME, Buscombe JR, Hilson AJ, Jones AL, Watkinson AF, Burroughs AK. Carcinoid tumour. Lancet. 1998 Sep;352(9130):799-805.

33 Davis Z, Moertel CG, McIlrath DC. The malignant carcinoid syndrome. Surg Gynecol Obstet. 1973 Oct;137(4):637-44.

34 Tomassetti P, Migliori M, Simoni P, Casadei $\mathrm{R}$, De Iasio R, Corinaldesi R, et al. Diagnostic value of plasma chromogranin $A$ in neuroendocrine tumours. Eur J Gastroenterol Hepatol. 2001 Jan;13(1):55-8

35 Tirosh A, Papadakis GZ, Millo C, Sadowski SM, Herscovitch P, Pacak K, et al. Association between neuroendocrine tumors biomarkers and primary tumor site and disease type based on total 68Ga-DOTATATE-Avid tumor volume measurements. Eur J Endocrinol. 2017 May;176(5):575-82.
36 Falconi M, Eriksson B, Kaltsas G, Bartsch DK, Capdevila J, Caplin M, et al.; Vienna Consensus Conference participants. ENETS Consensus Guidelines Update for the Management of Patients with Functional Pancreatic Neuroendocrine Tumors and Non-Functional Pancreatic Neuroendocrine Tumors. Neuroendocrinology. 2016;103(2):153-71.

37 Eriksson B, Oberg K, Stridsberg M. Tumor markers in neuroendocrine tumors. Digestion. 2000;62 Suppl 1:33-8.

38 Dromain C, de Baere T, Lumbroso J, Caillet $\mathrm{H}$, Laplanche A, Boige V, et al. Detection of liver metastases from endocrine tumors: a prospective comparison of somatostatin receptor scintigraphy, computed tomography, and magnetic resonance imaging. J Clin Oncol. 2005 Jan;23(1):70-8.

39 Ramage JK, Davies AH, Ardill J, Bax N, Caplin M, Grossman A, et al. Guidelines for the management of gastroenteropancreatic neuroendocrine (including carcinoid) tumours. Gut. 2005 Jun;54(suppl_4):iv1-16.

40 Öberg K, Knigge U, Kwekkeboom D, Perren A; ESMO Guidelines Working Group. Neuroendocrine gastro-entero-pancreatic tumors: ESMO Clinical Practice Guidelines for diagnosis, treatment and follow-up. Ann Oncol. 2012 Oct;23 Suppl 7:vii124-30.

41 Öberg K, Hellman P, Ferolla P, Papotti M; ESMO Guidelines Working Group. Neuroendocrine bronchial and thymic tumors: ESMO Clinical Practice Guidelines for diagnosis, treatment and follow-up. Ann Oncol. 2012 Oct;23 Suppl 7:vii120-3.

42 Keck KJ, Maxwell JE, Menda Y, Bellizzi A, Dillon J, O'Dorisio TM, et al. Identification of primary tumors in patients presenting with metastatic gastroenteropancreatic neuroendocrine tumors. Surgery. 2017 Jan;161(1):272-9.

43 Massimino KP, Han E, Pommier SJ, Pommier RF. Laparoscopic surgical exploration is an effective strategy for locating occult primary neuroendocrine tumors. Am J Surg. 2012 May;203(5):628-31.

44 Bartlett EK, Roses RE, Gupta M, Shah PK, Shah KK, Zaheer S, et al. Surgery for metastatic neuroendocrine tumors with occult primaries. J Surg Res. 2013 Sep;184(1):221-7.

45 Chambers AJ, Pasieka JL, Dixon E, Rorstad O. Role of imaging in the preoperative staging of small bowel neuroendocrine tumors. J Am Coll Surg. 2010 Nov;211(5):620-7.

46 Kamaoui I, De-Luca V, Ficarelli S, Mennesson N, Lombard-Bohas C, Pilleul F. Value of CT enteroclysis in suspected small-bowel carcinoid tumors. AJR Am J Roentgenol. 2010 Mar;194(3):629-33.

47 Antunes P, Ginj M, Zhang H, Waser B, Baum $\mathrm{RP}$, Reubi JC, et al. Are radiogallium-labelled DOTA-conjugated somatostatin analogues superior to those labelled with other radiometals? Eur J Nucl Med Mol Imaging. 2007 Jul;34(7):982-93.
48 Hofman MS, Kong G, Neels OC, Eu P, Hong E, Hicks RJ. High management impact of Ga68 DOTATATE (GaTate) PET/CT for imaging neuroendocrine and other somatostatin expressing tumours. J Med Imaging Radiat Oncol. 2012 Feb;56(1):40-7.

49 Pettinato C, Sarnelli A, Di Donna M, Civollani S, Nanni C, Montini G, et al. 68Ga-DOTANOC: biodistribution and dosimetry in patients affected by neuroendocrine tumors. Eur J Nucl Med Mol Imaging. 2008 Jan;35(1): $72-9$.

50 Naswa N, Sharma P, Kumar A, Nazar AH, Kumar R, Chumber S, et al. Gallium-68-DOTA-NOC PET/CT of patients with gastroenteropancreatic neuroendocrine tumors: a prospective single-center study. AJR Am J Roentgenol. 2011 Nov;197(5):1221-8.

51 Ambrosini V, Nanni C, Zompatori M, Campana D, Tomassetti $P$, Castellucci $P$, et al. (68) Ga-DOTA-NOC PET/CT in comparison with CT for the detection of bone metastasis in patients with neuroendocrine tumours. Eur J Nucl Med Mol Imaging. 2010 Apr;37(4): 722-7.

52 Prasad V, Ambrosini V, Hommann M, Hoersch D, Fanti S, Baum RP. Detection of unknown primary neuroendocrine tumours (CUP-NET) using (68)Ga-DOTA-NOC receptor PET/CT. Eur J Nucl Med Mol Imaging. 2010 Jan;37(1):67-77.

53 Gabriel M, Decristoforo C, Kendler D, Dobrozemsky G, Heute D, Uprimny C, et al. 68Ga-DOTA-Tyr3-octreotide PET in neuroendocrine tumors: comparison with somatostatin receptor scintigraphy and CT. J Nucl Med. 2007 Apr;48(4):508-18.

54 Ruf J, Heuck F, Schiefer J, Denecke T, Elgeti $\mathrm{F}$, Pascher A, et al. Impact of Multiphase 68Ga-DOTATOC-PET/CT on therapy management in patients with neuroendocrine tumors. Neuroendocrinology. 2010;91(1):1019.

55 Sampathirao N, Basu S. MIB-1 index-stratified assessment of dual-tracer PET/CT with 68Ga-DOTATATE and 18F-FDG and multimodality anatomic imaging in metastatic neuroendocrine tumors of unknown primary in a PRRT workup setting. J Nucl Med Technol. 2017 Mar;45(1):34-41.

56 Abgral R, Leboulleux S, Déandreis D, Aupérin A, Lumbroso J, Dromain C, et al. Performance of (18)fluorodeoxyglucose-positron emission tomography and somatostatin receptor scintigraphy for high Ki67 $(\geq 10 \%)$ well-differentiated endocrine carcinoma staging. J Clin Endocrinol Metab. 2011 Mar; 96(3):665-71.

57 Kayani I, Bomanji JB, Groves A, Conway G, Gacinovic S, Win T, et al. Functional imaging of neuroendocrine tumors with combined PET/CT using 68Ga-DOTATATE (DOTADPhe1,Tyr3-octreotate) and 18F-FDG. Cancer. 2008 Jun;112(11):2447-55. 
58 Becherer A, Szabó M, Karanikas G, Wunderbaldinger $\mathrm{P}$, Angelberger $\mathrm{P}$, Raderer M, et al. Imaging of advanced neuroendocrine tumors with (18)F-FDOPA PET. J Nucl Med. 2004 Jul;45(7):1161-7.

59 Imperiale A, Rust E, Gabriel S, Detour J, Goichot B, Duclos B, et al. 18F-fluorodihydroxyphenylalanine $\mathrm{PET} / \mathrm{CT}$ in patients with neuroendocrine tumors of unknown origin: relation to tumor origin and differentiation. J Nucl Med. 2014 Mar;55(3):367-72.

60 Duerr EM, Mizukami Y, Ng A, Xavier RJ, Kikuchi H, Deshpande V, et al. Defining molecular classifications and targets in gastroenteropancreatic neuroendocrine tumors through DNA microarray analysis. Endocr Relat Cancer. 2008 Mar;15(1):243-56.

61 Kaemmerer D, Posorski N, von Eggeling F, Ernst G, Hörsch D, Baum RP, et al. The search for the primary tumor in metastasized gastroenteropancreatic neuroendocrine neoplasm. Clin Exp Metastasis. 2014 Oct;31(7):817-27.

62 Sherman SK, Maxwell JE, Carr JC, Wang D, Bellizzi AM, Sue O'Dorisio M, et al. Gene expression accurately distinguishes liver metastases of small bowel and pancreas neuroendocrine tumors. Clin Exp Metastasis. 2014 Dec; 31(8):935-44.

63 Kerr SE, Schnabel CA, Sullivan PS, Zhang Y, Huang VJ, Erlander MG, et al. A 92-gene cancer classifier predicts the site of origin for neuroendocrine tumors. Mod Pathol. 2014 Jan; 27(1):44-54.

64 Francis JM, Kiezun A, Ramos AH, Serra S, Pedamallu CS, Qian ZR, et al. Somatic mutation of CDKN1B in small intestine neuroendocrine tumors. Nat Genet. 2013 Dec;45(12): 1483-6.

65 Karpathakis A, Dibra H, Pipinikas C, Feber A, Morris T, Francis J, et al. Prognostic Impact of Novel Molecular Subtypes of Small Intestinal Neuroendocrine Tumor. Clin Cancer Res. 2016 Jan;22(1):250-8.

66 Jiao Y, Shi C, Edil BH, de Wilde RF, Klimstra DS, Maitra A, et al. DAXX/ATRX, MEN1, and mTOR pathway genes are frequently altered in pancreatic neuroendocrine tumors. Science. 2011 Mar;331(6021):1199-203.

67 Karpathakis A, Dibra H, Thirlwell C. Neuroendocrine tumours: cracking the epigenetic code. Endocr Relat Cancer. 2013 May;20(3): R65-82.

68 Moore PS, Missiaglia E, Antonello D, Zamò A, Zamboni G, Corleto V, et al. Role of disease-causing genes in sporadic pancreatic endocrine tumors: MEN1 and VHL. Genes Chromosomes Cancer. 2001 Oct;32(2):17781. [cited 2019 Aug 23].

69 Pipinikas CP, Dibra H, Karpathakis A, Feber A, Novelli M, Oukrif D, et al. Epigenetic dysregulation and poorer prognosis in DAXXdeficient pancreatic neuroendocrine tumours. Endocr Relat Cancer. 2015 Jun; 22(3):L13-8.

70 Karpathakis A, Dibra H, Pipinikas C, Feber A, Morris T, Francis J, et al. Progressive epigenetic dysregulation in neuroendocrine tu- mour liver metastases. Endocr Relat Cancer. 2017 Feb;24(2):L21-5.

71 Verdugo AD, Crona J, Starker L, Stålberg P, Åkerström G, Westin G, et al. Global DNA methylation patterns through an array-based approach in small intestinal neuroendocrine tumors. Endocr Relat Cancer. 2014 Jan; 21(1):L5-7.

72 Chatzimichali EA, Bessant C. Novel application of heuristic optimisation enables the creation and thorough evaluation of robust support vector machine ensembles for machine learning applications. Metabolomics. 2016; 12(1):16.

73 Berner AM, Pipinikas C, Karpathakis A, Dibra H, Moghul I, Webster A, et al. PUnNETS (Prediction of Unknown Neuroendocrine Tumour Site) - A DNA Methylation-Based Classifier. ENETs Annual Conference. Barcelona, Spain; 2019; [cited 2019 Aug 23]. Available from: https://www.enets.org/punnetsprediction-of-unknown-neuroendocrine-tumour-site-a-dna-methylation-based-classifier.html.

74 Moran S, Martínez-Cardús A, Sayols S, Musulén E, Balañá C, Estival-Gonzalez A, et al. Epigenetic profiling to classify cancer of unknown primary: a multicentre, retrospective analysis. Lancet Oncol. 2016 Oct;17(10): 1386-95.

75 Fairweather M, Swanson R, Wang J, Brais LK, Dutton T, Kulke MH, et al. Management of Neuroendocrine Tumor Liver Metastases: Long-Term Outcomes and Prognostic Factors from a Large Prospective Database. Ann Surg Oncol. 2017 Aug;24(8):2319-25.

76 Modlin IM, Pavel M, Kidd M, Gustafsson BI. Review article: somatostatin analogs in the treatment of gastroenteropancreatic neuroendocrine (carcinoid) tumors. Aliment Pharmacol Ther. 2009 Oct;31(2):169-88.

77 Rinke A, Müller HH, Schade-Brittinger C, Klose KJ, Barth P, Wied M, et al.; PROMID Study Group. Placebo-controlled, doubleblind, prospective, randomized study on the effect of octreotide LAR in the control of tumor growth in patients with metastatic neuroendocrine midgut tumors: a report from the PROMID Study Group. J Clin Oncol. 2009 Oct;27(28):4656-63.

78 Caplin ME, Pavel M, Ćwikła JB, Phan AT, Raderer M, Sedláčková E, et al.; CLARINET Investigators. Lanreotide in metastatic enteropancreatic neuroendocrine tumors. N Engl J Med. 2014 Jul;371(3):224-33.

79 Turner NC, Strauss SJ, Sarker D, Gillmore R, Kirkwood A, Hackshaw A, et al. Chemotherapy with 5-fluorouracil, cisplatin and streptozocin for neuroendocrine tumours. Br J Cancer. 2010 Mar; 102(7):1106-12.

80 Kouvaraki MA, Ajani JA, Hoff P, Wolff R, Evans DB, Lozano R, et al. Fluorouracil, doxorubicin, and streptozocin in the treatment of patients with locally advanced and metastatic pancreatic endocrine carcinomas. J Clin Oncol. 2004 Dec;22(23):476271.
81 Fjällskog ML, Janson ET, Falkmer UG, Vatn MH, Öberg KE, Eriksson BK. Treatment with combined streptozotocin and liposomal doxorubicin in metastatic endocrine pancreatic tumors. Neuroendocrinology. 2008; 88(1):53-8.

82 Sun W, Lipsitz S, Catalano P, Mailliard JA, Haller DG; Eastern Cooperative Oncology Group. Phase II/III study of doxorubicin with fluorouracil compared with streptozocin with fluorouracil or dacarbazine in the treatment of advanced carcinoid tumors: Eastern Cooperative Oncology Group Study E1281. J Clin Oncol. 2005 Aug;23(22):4897-904.

83 Stoyianni A, Pentheroudakis G, Pavlidis N. Neuroendocrine carcinoma of unknown primary: a systematic review of the literature and a comparative study with other neuroendocrine tumors. Cancer Treat Rev. 2011 Aug; 37(5):358-65.

84 Yao JC, Shah MH, Ito T, Bohas CL, Wolin EM, Van Cutsem E, et al.; RAD001 in Advanced Neuroendocrine Tumors, Third Trial (RADIANT-3) Study Group. Everolimus for advanced pancreatic neuroendocrine tumors. N Engl J Med. 2011 Feb;364(6):514-23.

85 Yao JC, Pavel M, Lombard-Bohas C, Van Cutsem E, Voi M, Brandt U, et al. Everolimus for the Treatment of Advanced Pancreatic Neuroendocrine Tumors: Overall Survival and Circulating Biomarkers From the Randomized, Phase III RADIANT-3 Study. J Clin Oncol. 2016 Nov;34(32):3906-13.

86 Raymond E, Dahan L, Raoul JL, Bang YJ, Borbath I, Lombard-Bohas C, et al. Sunitinib malate for the treatment of pancreatic neuroendocrine tumors. N Engl J Med. 2011 Feb; 364(6):501-13.

87 Singh S, Carnaghi C, Buzzoni R, Pommier RF, Raderer M, Tomasek J, et al.; RAD001 in Advanced Neuroendocrine Tumors, Fourth Trial (RADIANT-4) Study Group. Everolimus in Neuroendocrine Tumors of the Gastrointestinal Tract and Unknown Primary. Neuroendocrinology. 2018;106(3):211-20.

88 Kulke MH, Lenz HJ, Meropol NJ, Posey J, Ryan DP, Picus J, et al. Activity of sunitinib in patients with advanced neuroendocrine tumors. J Clin Oncol. 2008 Jul;26(20):340310.

89 Yoo C, Cho H, Song MJ, Hong SM, Kim KP, Chang HM, et al. Efficacy and safety of everolimus and sunitinib in patients with gastroenteropancreatic neuroendocrine tumor. Cancer Chemother Pharmacol. 2017 Jan;79(1): 139-46.

90 Alexandraki KI, Tsoli M, Kyriakopoulos G, Angelousi A, Nikolopoulos G, Kolomodi D, et al. Current concepts in the diagnosis and management of neuroendocrine neoplasms of unknown primary. Minerva Endocrinol. 2019, Epub ahead of print.

91 Chan ES, Alexander J, Swanson PE, Jain D, Yeh MM. PDX-1, CDX-2, TTF-1, and CK7: a reliable immunohistochemical panel for pancreatic neuroendocrine neoplasms. Am J Surg Pathol. 2012 May;36(5):737-43. 